\title{
Strategies for Reducing Energy Consumption in a Student Cafeteria in a Hot-Humid Climate: A Case Study
}

\author{
Mohammed Alhaji Mohammed ${ }^{* 1}$, Ismail Mohammad Budaiwi ${ }^{2}$ \\ ${ }^{1}$ School of Architecture Planning and Landscape, \\ Newcastle University, Newcastle Upon Tyne, UK \\ e-mail:mamkol@yahoo.com \\ ${ }^{2}$ Architectural Engineering Department, \\ King Fahd University of Petroleum and Minerals, Dhahran, Saudi Arabia
}

Cite as: Mohammed, M.A., Budaiwi, I.M., Strategies for Reducing Energy Consumption in a Student Cafeteria in a Hot-Humid Climate: A Case Study, J. sustain. dev. energy water environ. syst., 1(1), pp 14-26, 2013, http://dx.doi.org/10.13044/j.sdewes.2013.01.0002

\begin{abstract}
Increasing attention is being given to energy consumption and potential for energy savings in public buildings in order to improve energy performance. Due to their size and functional requirements, public buildings especially cafeteria facilities tend to consume a significant amount of energy. Furthermore, due to their operational characteristics and construction pattern, unnecessary energy is likely to be used for maintaining acceptable indoor environmental quality. In this study, a student cafeteria at King Fahd University of Petroleum and Minerals, Saudi Arabia, was selected for the assessment of its energy performance and potential energy conservation opportunities. Energy simulation software Visual DOE 4.1 was used to develop an energy performance model for assessing various energy conservation measures pertinent to the building envelope and HVAC system design. Data required for setting up the model were gathered through simple energy audits. The architectural and mechanical drawings and the history of electrical consumption were collected. Various energy conservation strategies were then implemented including standards, single and combined energy conservation measures. These measures resulted in a combined design saving of $27.4 \%$, the HVAC system saving $10.6 \%$, implementation of standards saving about $16.7 \%$, lighting $6.6 \%$, equipment $2.6 \%$, insulation $2.5 \%$ and glazing $1.4 \%$. Based on these results, it is apparent that there is a significant potential for improving energy performance and justification to employ the suggested measures for achieving substantial energy savings and minimize energy consumption.
\end{abstract}

\section{KEYWORDS}

Energy Consumption, Cafeteria Buildings, Integrated Design, HVAC, Optimization

\section{INTRODUCTION}

Energy is the most important resource to be conserved in order to reduce expenses and greenhouse gas emission in any facility. Public facilities like cafeterias which are self-service restaurants, are one of the major consumers of energy. Restaurants have been ranked among the most energy-intensive commercial spaces in California in the United States, owing to their high requirement for heating, cooling, lighting and sanitation, which together accounts for the major segment of average restaurant's electricity and natural gas consumption [1]. According to data from Pacific Gas and Electric's Food Service Technology Centre, $80 \%$ of the $\$ 10$ billion annual energy bill for the commercial food service sector in the United States is expended by inefficient food cooking, holding and storage equipment [2]. In addition, Power use per square foot in a

\footnotetext{
* Corresponding author
} 
food service facility is greater than in any other kind of commercial building and more than triple what a hospital utilizes per square foot and at least six times what an office facility uses per square foot in the United State [3].

However, Energy conservation in commercial buildings is increasingly becoming an issue of concern in Saudi Arabia, not just for reducing the depletion of oil and gas but because of the environmental impact due to energy consumption. Buildings in a desert climate such as that of Saudi Arabia are subjected not only to high ambient air temperatures, but also to strong solar radiation throughout the day. This may draw the attention of designers and architects to carefully consider the design of the various building components in order to minimize heat gain into buildings [4]. Energy efficient design strategies in hot and humid climates should consider the optimization in the building envelope, the lighting, and the HVAC system designs. Since the building envelope represents all the exposed building components that separate the indoor and the outdoor harsh environments, thus requiring more attention in the design stage.

Furthermore, appropriate use of thermal insulation in buildings improves thermal comfort and reduces operating costs. The degree of energy savings due to thermal insulation varies according to the building type, the climatic conditions at which the building is located, as well as the insulating material type, thickness, and location [5]. Insulation of building envelopes, both opaque and transparent, is the most important strategy for increasing energy conservation. Insulation of walls, roof, attic, basement walls and even foundations is one of the most essential features of energy-efficient buildings [6]. The use of thermal insulation in building walls and roof not only contributes in reducing the required air-conditioning system size but also in reducing the annual energy cost [5]. Hence, an integrated and efficient building envelope with appropriate window and glazing design can reduce not only the energy and operating costs of a facility, but also the size and cost of the HVAC system needed to maintain adequate building pressurization, good indoor air quality and comfortable thermal comfort conditions for building occupants [7].

In hot climates, a considerable amount of heat and solar radiation is gained through windows. As such, low-emittance double-glazed windows are recommended for energy efficiency especially in large glazed buildings, as more energy-efficient windows can be beneficial in both reducing the energy use and improving the indoor comfort levels [8]. Thus, large glazing in buildings will result in a small amount of heat conduction through the opaque part of the building [9]. The operating cost of lighting systems depends on the level of lighting needed in the building and the availability of daylight. The electric energy consumption depends on the needed intensity and the amount of light delivered by the lighting system as a function of the electric power. Therefore, the energy consumption of lighting systems is characterized by the electric efficiency in Lumen/W. It is recommended that the schedule of lighting and equipment should be adjusted in office buildings so that they are turned off during unoccupied or low occupancy hours, during lunch and other break times [8]. However, this is probably problematic in some functions especially food storage in restaurant, but it can be solved by supplying electricity to only the required section of a building during lunch and breaks.

In harsh climatic conditions such as Saudi Arabia, a substantial share of energy goes to the air-conditioning of buildings in order to provide an acceptable level of thermal comfort. This air-conditioning load can be reduced through many means; notably the proper design and selection of material for the building envelope and its components. In addition, the excessive demand for air conditioning in the Kingdom of Saudi Arabia is a direct result of the extreme temperatures during summer, when the ambient temperature frequently reaches $46^{\circ} \mathrm{C}$ at night. About $65 \%$ of the electric energy generated in Saudi 
Arabia is used for operating buildings and 65\% of this energy is consumed by air conditioning [10]. In the Kingdom of Saudi Arabia, the largest energy consumer, due to climate conditions is the HVAC unit which consumes about $60 \%$ of the total energy. According to a study conducted [11], the energy needed to run the HVAC unit and achieve comfort was reduced by $444.29 \mathrm{MWh} / \mathrm{yr}$ in the low energy model compared to the base-case which represents a clear evidence of the effectiveness of the applied energy saving strategies. In many situations buildings are over-cooled or the HVAC system is kept running for a much longer time than needed [12].

The optimization of individual systems alone cannot deliver the required level of energy conservation without input from operational strategies and adoption of energy standards and codes. Because of the ease of installation and the increasing capabilities of electronic controllers, operational strategies that could be programmed for built-up systems or pre-packaged HVAC equipment are of particular interest [13]. Thermal comfort is not achieved due to improper operation practices coupled with poor maintenance [12]. Changing HVAC operating strategies work equally well and can result in savings through reduced equipment sizes as a result of peak reductions [8]. Computer simulations of a particular operational strategy, in advance, provide insights that are instrumental in realizing the expected energy efficiency from a particular operational strategy and justify making the additional investment [13].

Building Energy Codes are a means of guiding and specifying the direction for improving energy efficient practices and offer minimum building requirements that are cost-effective in saving energy. The Implementation and enforcement of such codes will bring about fewer power plants and natural resources being used to provide electricity and natural gas and consequently reduces emissions to the atmosphere. Building energy codes contribute to sustainability by saving energy and protecting the environment. Energy codes are effective in reducing per capita energy usage and dictate requirements for the building's envelope, mechanical, and lighting requirements [14]. But the major issue remains the disparity between applications of optimization strategies simultaneously and in isolation. The search for optimum energy performance requires a rational application of parameters which together optimize the performance of the whole building's systems. The relationship between various energy performance strategies, optimization of various building systems in isolation will not reflect the real interaction between them compared to an integrated design approach. It is therefore necessary to apply an integrated approach to the process of optimizing the building design and evaluating its performance [9].

\section{METHODOLOGY}

The optimization of building energy performance involves an integrated design approach to curtail energy consumption while meeting all the requirements of the occupants of the facility. Integrated design is a significant aspect of optimizing energy performance, including equipment selection, as decisions made in one area will affect the others. The optimization of efficiency measures should not only consider the direct impact of these measures on energy consumption but also their impact on each other. This is because optimizing these measures in isolation does not reflect the real interaction and conflict between them which may negatively affect the energy consumption [9]. The energy consumption per capita of the bulk of the population is increasing significantly especially in the developed world. Recently Energy growth in developing countries has also become conscious due to major developments in several sectors such as commercial, residential, industrial and agriculture. Therefore, energy conservation could be achieved by adopting an 
applied technique in energy utilization without affecting the standard of living in the society.

The energy interactions between heating, cooling and lighting together with the equipment of a building are quite complex and the process of modelling such a system requires many input parameters [15]. Therefore, the structure of the computer program Visual DOE 4.1 has all the required capability to predict the energy conservation measures with the above mentioned parameters. The methodology employed in this study includes conducting a brief energy audit analysis of the building including collection of all the necessary information like architectural and mechanical drawings, electric consumption history, cafeteria schedules from projects, maintenance and food services departments respectively. Based on the information collected a base-case of the cafeteria building was developed using the selected energy simulation software. Various energy conservation measures have been employed including lighting, equipment and envelope, individually and integrated, where all Energy Conservation Measures (ECMs) are applied simultaneously. The base-case energy consumption has been compared with standards of lighting, equipment, envelope and HVAC system parameters from American Society for Heating, Refrigerating, and Air-Conditioning Engineers (ASHRAE), and International Energy Conservation Code (IECC).

\section{THE MODELLED BUILDING DESCRIPTION}

A student Cafeteria at King Fahd University of Petroleum and Minerals (KFUPM) has been selected for the study. The cafeteria is characterized by having a high window to wall ratio of about $47 \%$ and is completely dependent on mechanical means for ventilation as a large percentage of its envelope is dominated by fixed glazing without any window. This together with the function of the cafeteria as a public place that accommodates hundreds of students for breakfast, lunch and dinner every day, there is a need to optimize the current energy conservation strategies used in the cafeteria. The HVAC system used in the building is a huge multi system with four air handling units; two serving eight zones each, and the other two serving seven and one zone totaling to 24 zones in the building.

The cafeteria building was designed to contain all functions in a single floor with overall dimension of $106 \mathrm{~m} \times 79 \mathrm{~m}$ and total restaurant area is $5662 \mathrm{~m} 2$ as illustrated in Figure 1. The major function in the building is the student dining, and it is divided into two main zones. The First one is food Storage zone that is used for the preparation of the imported foods from a kitchen located in different place. The second zone is the restaurant or cafeteria dining hall which is used mainly by the students for eating. Besides that, there are some facilities including administrative Offices, W.C, washing area, other Services. The building has 4 entrances (3 general entrances, and an entrance for loading dock and employees as illustrated in Figure 1. The building does not contain any kitchen but just storage, preparation and serving areas as food is supplied from the main kitchen of the university. The various parameters that constitute the cafeteria building system are presented in Table 1.

The Heating Ventilation and Air-conditioning System (HVAC) used in the cafeteria is constant volume, multi zone (reheat fan) chilled water system operated by pneumatic control. The HVAC system works for 24 hours a day. It has 6 reciprocating chillers, three work at a time while the remaining three serve as standby. A chiller is served by four compressors, each having 30 tonnes capacity. Therefore, the total capacity of each chiller is 120 tonnes. Every chiller has one condenser motor with capacity of 7.5 HP. There are four (4) Air Handling Units (AHU) in the building with AHU No 1( capacity $130 \mathrm{~kW}$ ) serving only one zone including offices, corridors and delivery areas, while AHU No 3 
and 4 (capacities 463 and $452 \mathrm{~kW}$ respectively) having eight zones and AHU No 2 (capacity $438 \mathrm{~kW}$ ) with seven zones.

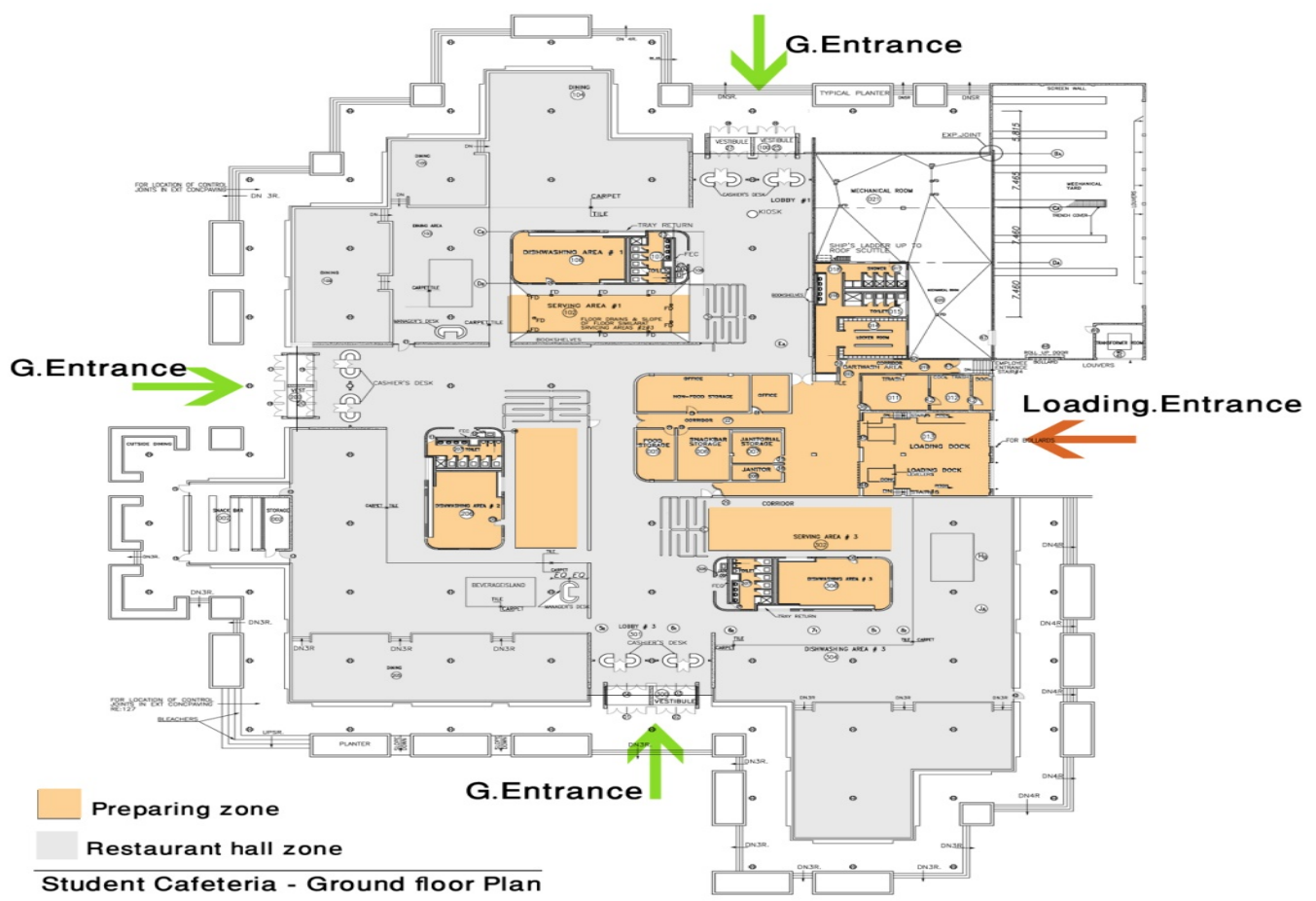

Figure 1: The Floor Plan of the Cafeteria showing various zones and entrances to the building.

Table 1: Cafeteria Building Descriptions

\begin{tabular}{|c|c|c|}
\hline$S / N$ & Building Parameters & Values \\
\hline 1. & Number of storeys & One \\
\hline 2. & Total area & $5642 \mathrm{~m}^{2}$ \\
\hline 3. & Floor height & $5 \mathrm{~m}$ \\
\hline 4. & orientation & North-South \\
\hline \multicolumn{3}{|c|}{ Building skin } \\
\hline 5. & Wall & $0.527 \mathrm{~W} / \mathrm{m}^{2} \mathrm{C}$ \\
\hline 6. & Roof & $0.531 \mathrm{~W} / \mathrm{m}^{2} \mathrm{C}$ \\
\hline 7. & Glazing & $2.742 \mathrm{~W} / \mathrm{m}^{2} \mathrm{C}$ \\
\hline 8. & SC & 0.81 \\
\hline 9. & SHGC & 0.698 \\
\hline 10. & Transmittance & 0.781 \\
\hline 11. & Infiltration rate & $0.10 \mathrm{ACH}$ \\
\hline 12. & Thermal zones & 24 \\
\hline \multicolumn{3}{|c|}{ Building Systems } \\
\hline 13. & Equipment & $10.89 \mathrm{~W} / \mathrm{m}^{2}$ \\
\hline 14. & Lighting & $16.2 \mathrm{~W} / \mathrm{m}^{2}$ \\
\hline 15. & HVAC system & Constant Volume Reheat fan system \\
\hline 16. & Set point temperature & $20-21^{\circ} \mathrm{C}$ \\
\hline \multicolumn{3}{|c|}{ Building Operations } \\
\hline 17. & Schedules & 63 hours per week \\
\hline 18. & Occupancies & $4 \mathrm{~m}^{2} /$ person \\
\hline
\end{tabular}

\section{Base-case Formulation}

The parameters for the base-case energy model of the student cafeteria includes lighting, equipment, cooling, pumps, fans, and hot water with total consumption of 3 , $722,485 \mathrm{~kW}$. Cooling load consumed the largest share of energy of about $66 \%$ of the total 
energy consumption, then lighting and fans consumed $14 \%$ each, and equipment $5 \%$, hot water $1 \%$, while pumps consumed a negligible percentage as illustrated in Table 2 and Figure 2.

Table 2: Base case Energy consumption Parameters

\begin{tabular}{c|ccccccc}
\hline Alternatives & Lights & Equipment & Cooling & Pumps/Aux & Fans & Hot Water & Total \\
\hline kW & 515831 & 197448 & 2448628 & 10136 & 517592 & 32850 & 3722485 \\
\hline
\end{tabular}

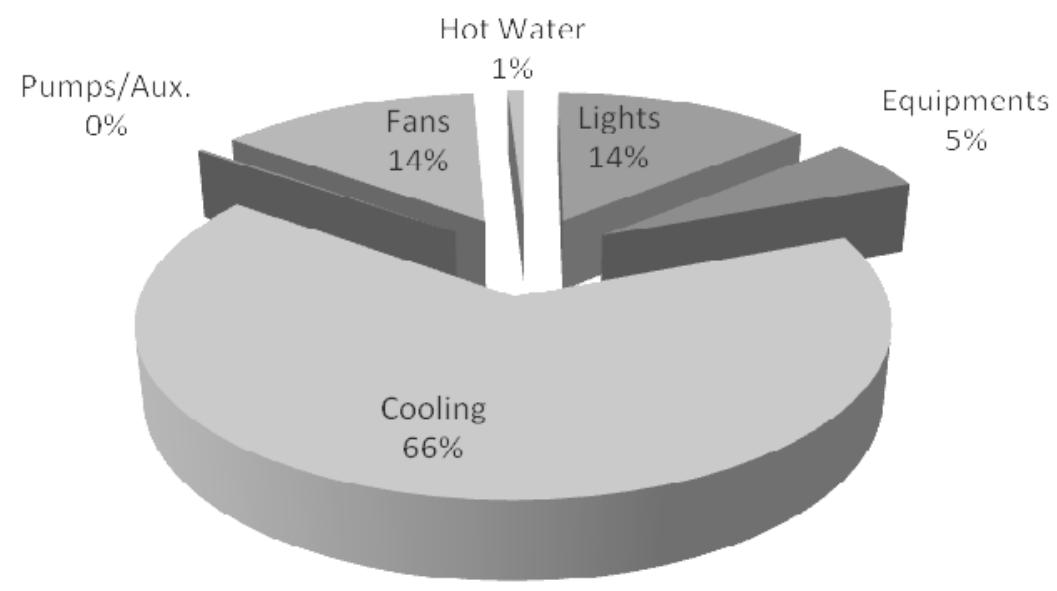

Figure 2: Base Case Electricity Consumption $(\mathrm{kW} / \mathrm{H})$

\section{Energy audit}

The main objective of an energy audit is to balance the input energy (i.e. electricity) against known uses. Energy savings can then be easily achieved through the adjustments of these uses. The auditing process generally includes: measurements and analysis of consumption, modifications, implementation of energy management and energy conservation techniques [16]. A Brief energy audit has been carried out in order to identify the required information for the modeling of the cafeteria base-case. The electricity consumption for the year 2009 has been collected from the electrical unit of the maintenance departments of the KFUPM. This electrical bill has been compared with the base case model of the building to ensure the capability of the software and correctness of the information provided. With a little adjustment the relationship is shown in Table 3 and Figure 3.

Table 3: Relationship between Billing History and Base case

\begin{tabular}{l|cccccccccccc}
\hline \multicolumn{1}{c|}{ Months } & Jan & Feb & Mar & Apr & May & Jun & Jul & Aug & Sept & Oct & Nov & Dec \\
\hline Base case & 217931 & 213931 & 300252 & 323315 & 360287 & 351879 & 361748 & 355854 & 330891 & 346701 & 281881 & 277797 \\
$\begin{array}{l}\text { Billing } \\
\text { History (kW) }\end{array}$ & 262200 & 358800 & 179400 & 237360 & 237360 & 311880 & 375360 & 322920 & 383640 & 295320 & 298080 & 458160 \\
\hline
\end{tabular}




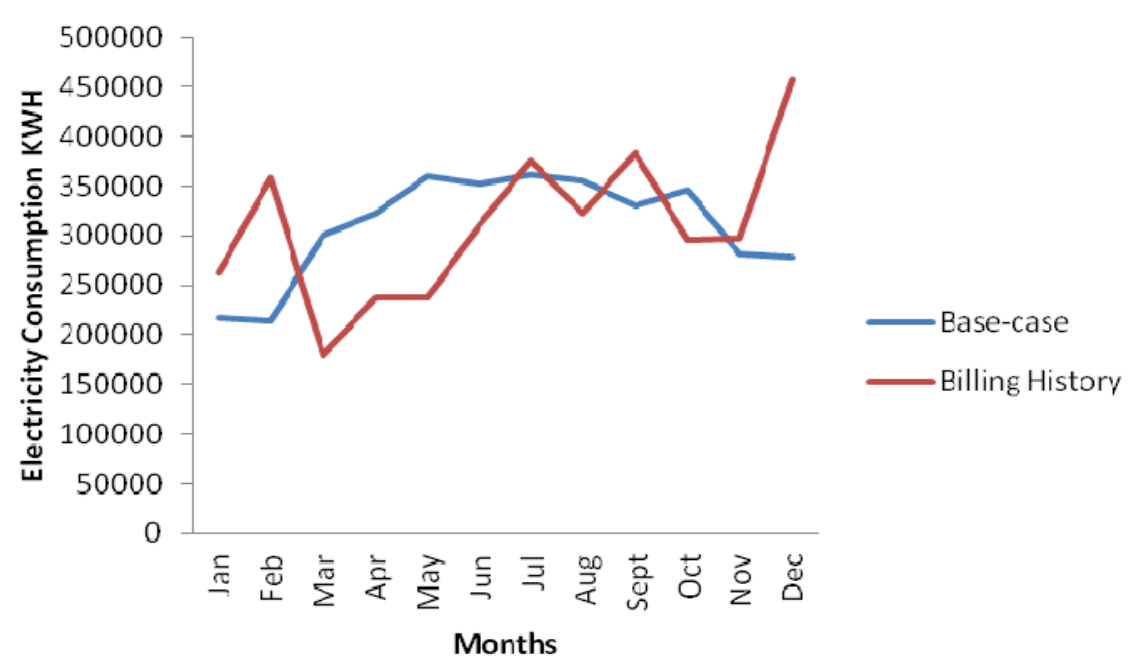

Figure 3: Relationship between Billing History and the Base-case

\section{CAFETERIA RELEVANT BUILDING CODES AND STANDARDS}

There are many standards and codes related to cafeteria energy design including those provided by agencies and organizations such as; American Society for Heating, Refrigerating, and Air-Conditioning Engineers (ASHRAE), International Energy Conservation Code (IECC), Illumination Engineers Society of North America (IESNA), International Building Code, Facilities Standards for the Public Building Service, etc. These organizations have developed codes and standards affecting the design of Food Service space types. These codes and standards are minimum requirements; architects, engineers, and consultants should consider exceeding the applicable requirements whenever possible. Table 4 shows various energy conservation standards related to cafeteria design $[17,18]$

Table 4: Cafeteria Energy Standards

\begin{tabular}{l|lll}
\hline S/N & & Building Parameters & \multicolumn{1}{c}{ Values (ASHRAE) } \\
\hline & & Building skin & \\
$\mathbf{1 .}$ & Wall & & $0.580 \mathrm{~W} / \mathrm{m}^{2} \mathrm{C}$ \\
$\mathbf{2 .}$ & Roof & & $0.065 \mathrm{~W} / \mathrm{m}^{2} \mathrm{C}$ \\
$\mathbf{3 .}$ & Floors & & $0.322 \mathrm{~W} / \mathrm{m}^{2} \mathrm{C}$ \\
$\mathbf{4 .}$ & Glazing & & $0.7 \mathrm{~W} / \mathrm{m}^{2} \mathrm{C}$ \\
$\mathbf{5 .}$ & SC & & 0.81 \\
$\mathbf{6 .}$ & SHGC & Building Systems & 0.4 \\
$\mathbf{7 .}$ & Transmittance & & 0.781 \\
$\mathbf{8 .}$ & Infiltration rate & & $0.10 \mathrm{ACH}$ \\
& & & \\
9. & Equipments (EPD) & Building Operations & $1.83 \mathrm{~W} / \mathrm{m}^{2}$ \\
$\mathbf{1 0 .}$ & Lighting (LPD) & & $14.0 \mathrm{~W} / \mathrm{m}^{2}$ \\
$\mathbf{1 1 .}$ & Set point temperature & & $23-25^{\circ} \mathrm{C}$ \\
& & & \\
12. & Occupancies & & $1 \mathrm{~m}^{2} / \mathrm{person}$ \\
\hline
\end{tabular}




\section{ANALYSIS AND DISCUSSION}

Cafeteria buildings remain one of the commercial buildings with the highest energy consumption, as it is ranked the most energy intensive commercial building in California USA [3]. When the building envelope parameters are designed with the purpose of optimizing the energy performance, the size and capacity of mechanical equipment can be reduced and, consequently, the electric power distribution may also be reduced. However, the optimum design of the building envelope will not necessarily lead to exemplary high energy performance due to the fact that the energy consumption is strongly influenced by the building systems and occupants [9]. Three different energy conservation approaches have been employed in order to select the best measure among them. These approaches include the application of existing standards, isolated application of various Energy Conservation Measures (ECMs), and integrated application of all the ECMs together.

\section{Application of Standards}

Building energy standards are a set of procedures and regulations that prescribe the energy performance of buildings [19]. They can be used to address the efficiency level of indi-vidual building systems, while building codes address the energy use of entire buildings or building systems such as heating, ventilation, and air conditioning [20]. Energy standards remains one of the most commonly used instruments for energy efficiency enhancement in buildings and can play a significant role [21]. Building energy standards can be used to fill the gap between existing building designs and increasing demand for sustainable energy efficient building [19]. Various standards including envelope, lighting, equipment and set point temperatures $[17,18]$ have been applied to the cafeteria, which resulted in conserving about $16.7 \%$ of the total energy consumption compared to the base-case. The monthly energy savings with the application of various standards in relation to the base-case is illustrated in Figure 4.

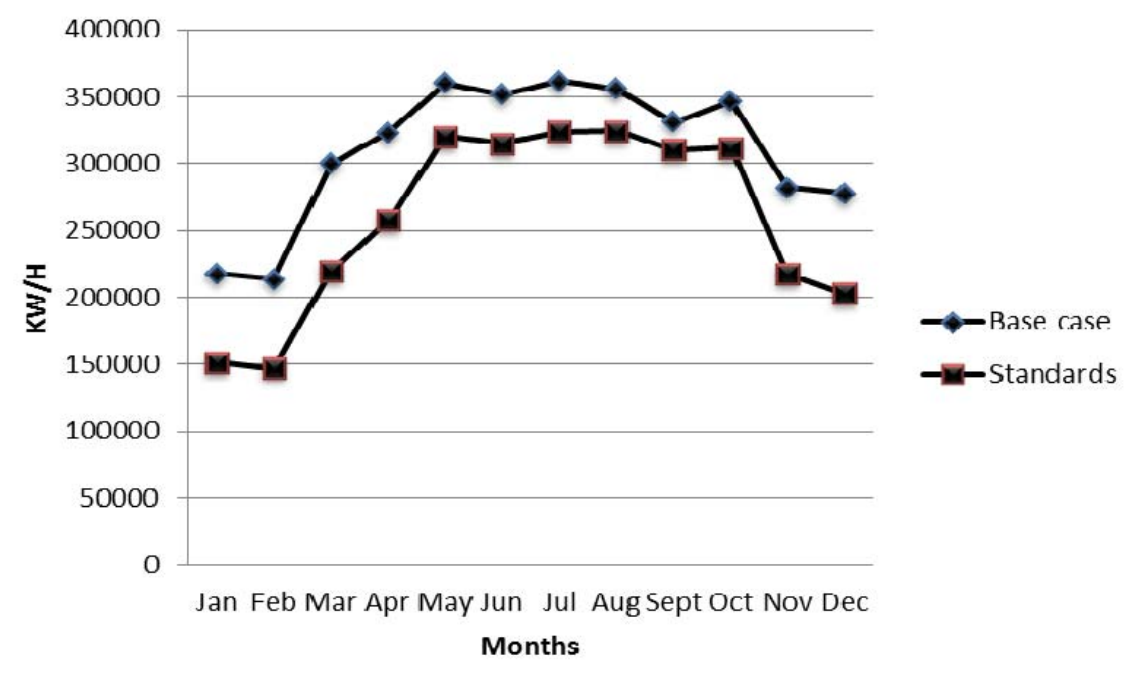

Figure 4: Energy Conservation Standard ECMs in Relation to the Base-case

\section{Isolated Application of ECMs}

Different energy conservation measures have been applied to the cafeteria separately to see their impact on the building's energy consumption. These individual parameters 
were measured in isolation with consideration of the other parameters. Lighting system in the cafeteria after adjusting the operation schedule from 12 hours to 9 hours operations saved about $6.6 \%$ electricity compared to the total energy consumption of the base-case. The remaining three ECMs including wall/roof glazing and equipment have no significant saving capacity compared to the HVAC system and standards, because together, it resulted in saving about $13.1 \%$ of the total energy consumption compared to the base-case as illustrated in Figure 5.

The HVAC system energy conservation strategy was achieved by adjusting the operating time before the cafeteria building is occupied for breakfast, lunch and dinner. Three different time schedules have been tested, including operating the HVAC system 1hour, 3hours, and 4 hours before occupancy. The result confirms that the strategy for operating the HVAC 1 hour before occupancy is not proper, because the building will not be comfortable enough within the early period of occupancy. Hence, 3 and 4 hours schedule is more comfortable to the occupants, even as they consume more energy compared to the 1 hour strategy. HVAC system has the highest energy saving percentage of $10.6 \%$ in isolation. This was achieved after the schedule of the system was changed from 24 hours operation to 15 hours operation (only in the daytime 4 hours before occupancy). The result for HVAC system energy conservation measure operating for 4 hours before occupancy is illustrated in Figure 6 and the comparative results for 1, 3, and 4 hours before occupancy in relation to the base-case is illustrated in Figure 7.

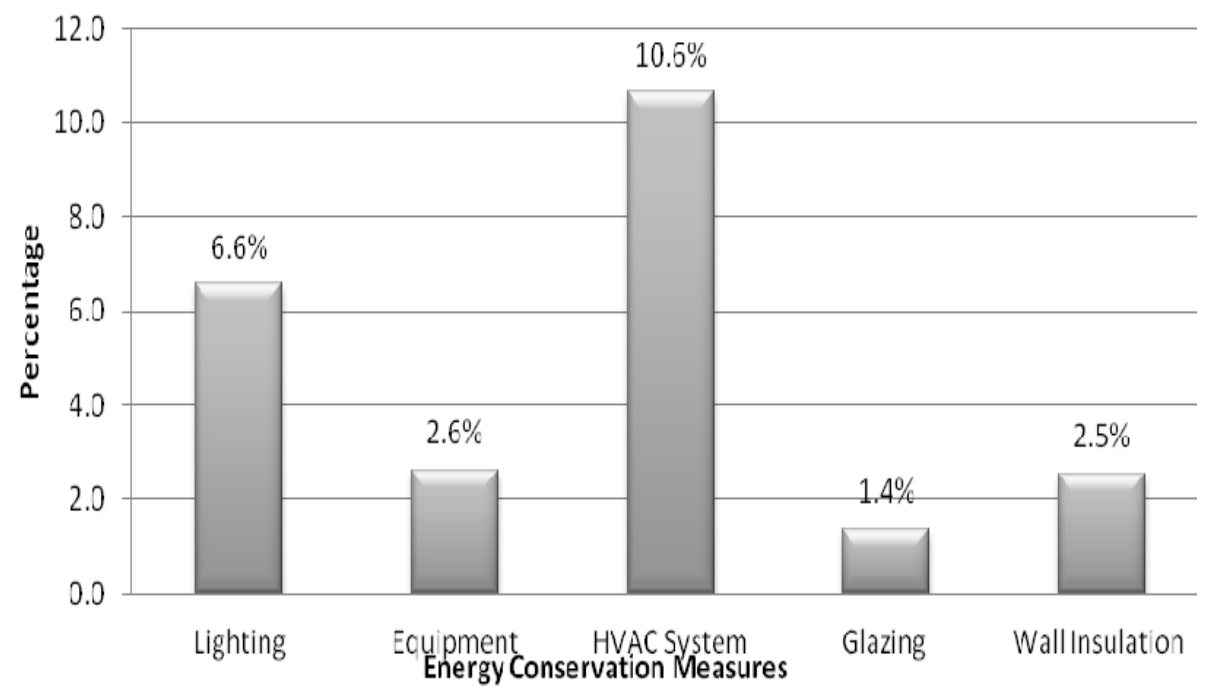

Figure 5: Energy Savings percentages of Isolated ECMs Compared to the Base-case 


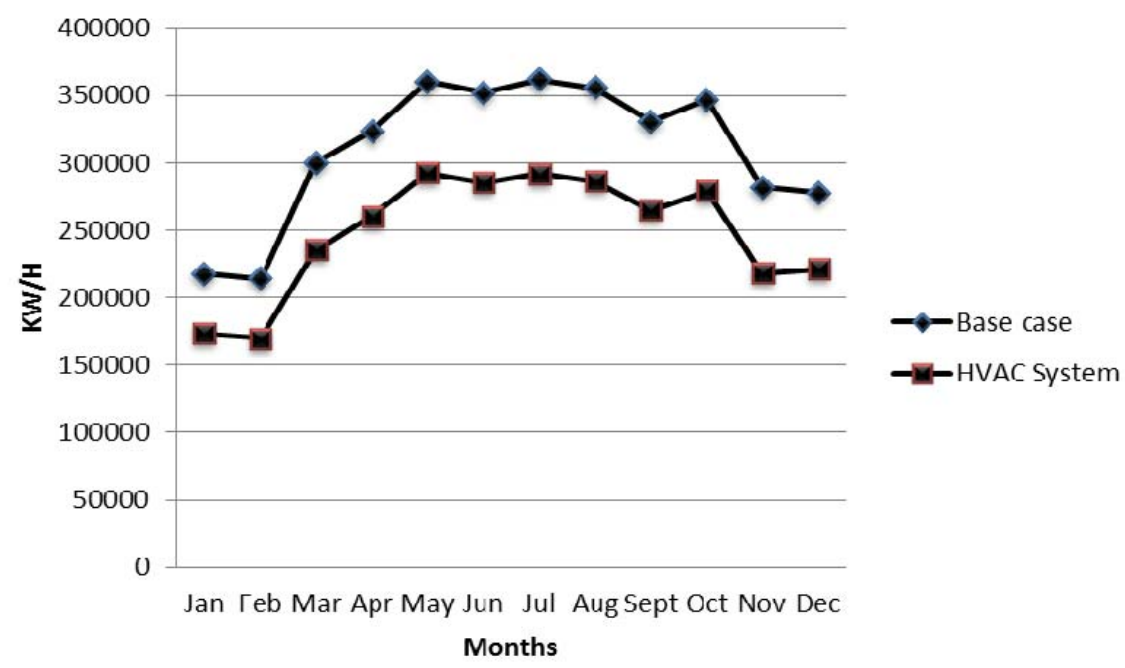

Figure 6: HVAC System ECM in Relation to the Base-case

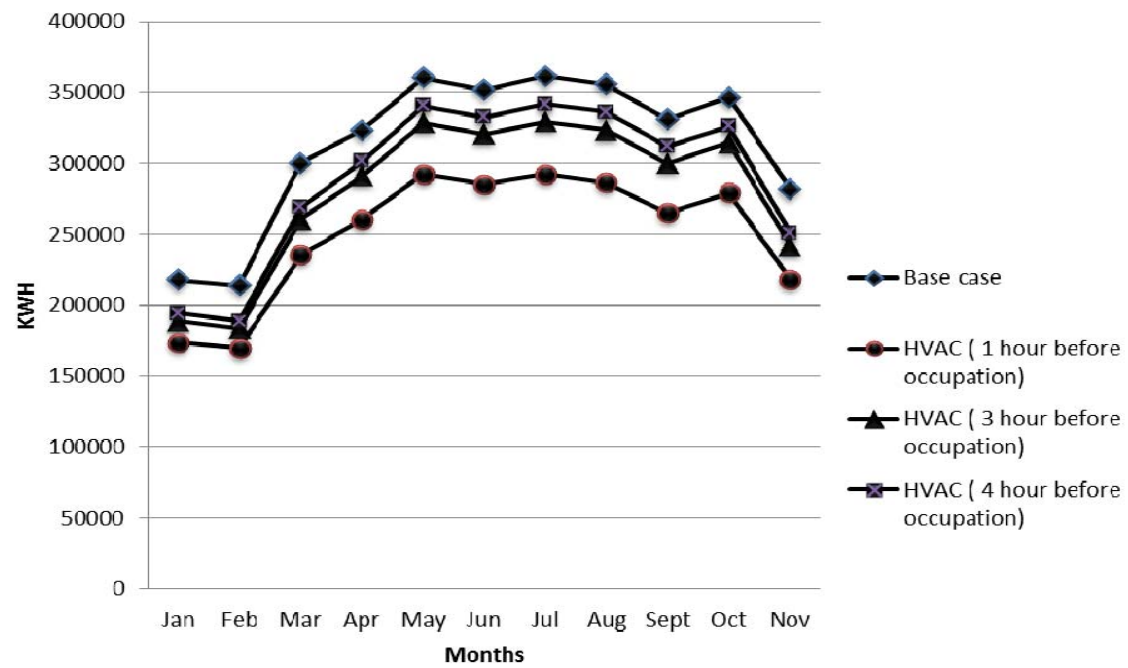

Figure 7: ECMs when HVAC System is ‘On’ in 1, 3, and 4 Hours before Occupancy in Relation to the Base-case

\section{Integrated Design of ECMs}

The search for the most favorable energy performance requires a logical application of parameters which together will optimize the performance of the entire building's systems, as it is necessary to apply an integrated approach to the process of optimizing building design and evaluating performance [9]. In this study, the adopted integrated building design approach has the highest energy saving percentage of $27.4 \%$ compared to the base-case, because it combines all the energy conservation measures together. However, the isolated application of energy conservation measures result in saving 23.7\% compared to the base-case. Thus, the integrated design results in saving 3.4\% compared to the isolated application of ECMs as illustrated in Figure 8 and 9. 


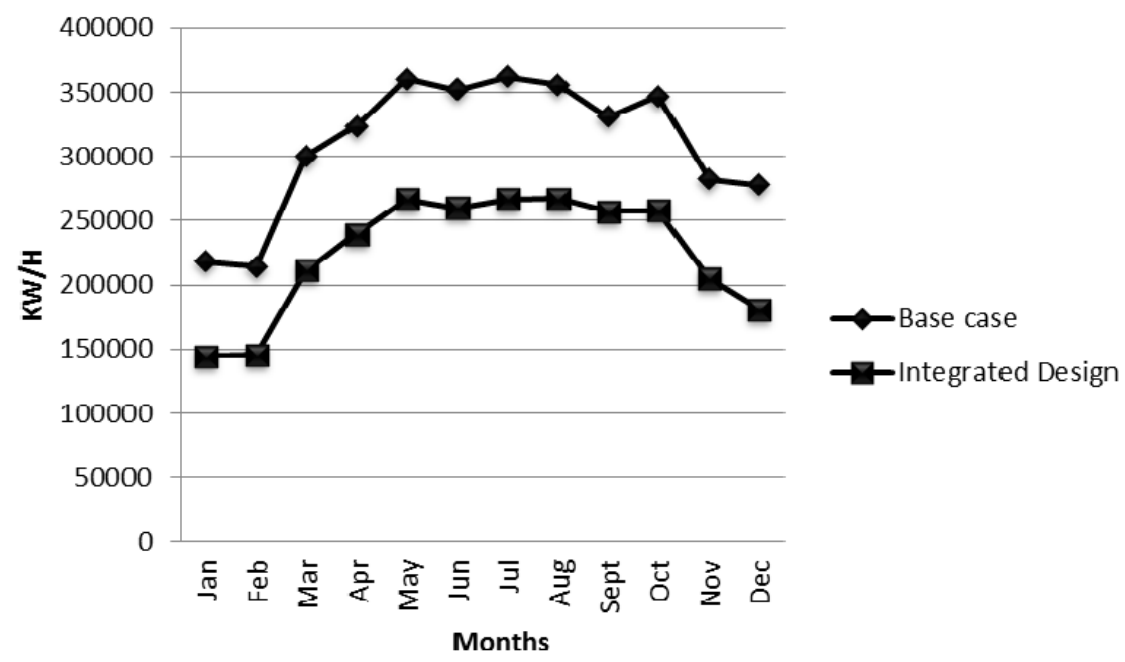

Figure 8: Integrated Design ECM in Relation to the Base-case

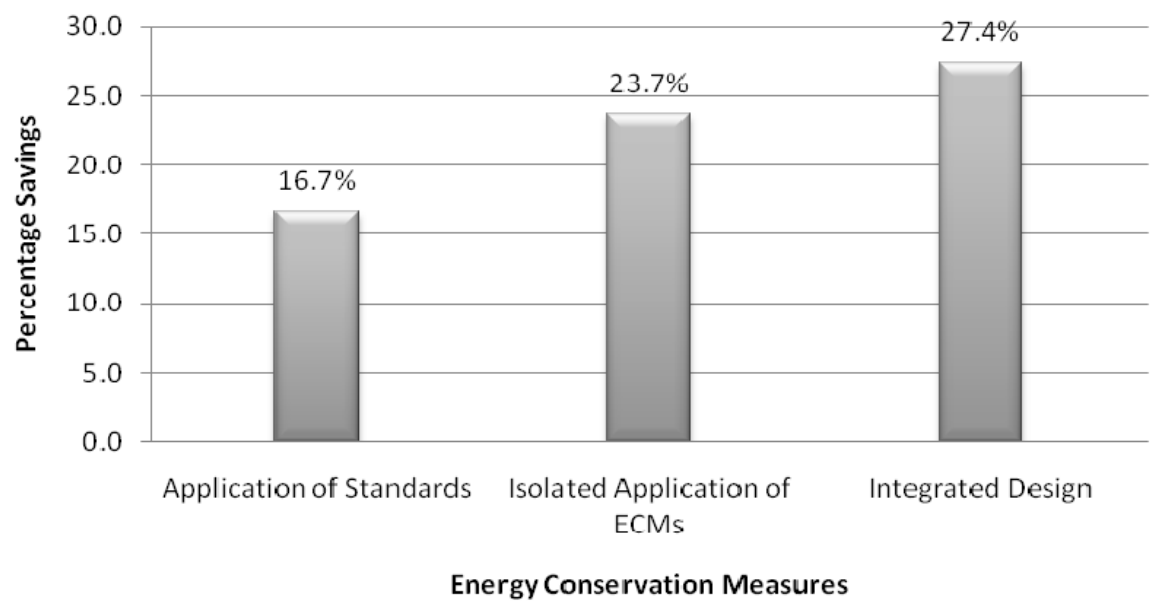

Figure 9: Comparative Analysis of Standards, Isolated and Integrated ECMs Compared to the Base-case

\section{CONCLUSION}

The investigation for improving energy performance of cafeteria buildings in hot and humid climate has provided the opportunity to explore various energy conservation measures and their relationships. The Visual DOE 4.1 software was used to accurately predict the energy performance of the building under study. The result obtained from the base-case simulation shows that, $66 \%$ of the electricity is consumed by cooling while fans and lighting constitutes $14 \%$ each. This is due to the large amount of internal and external heat gains. Even though the building is envelope dominated with $47 \%$ window to wall area, the energy saving through the envelope is minimal of only $9 \%$ compared to the total energy consumption of the base-case. This is due to $6 \mathrm{~m}$ exterior shading provided in form of eave projection.

Various energy conservation strategies have been applied including standards, isolated and integrated implementation of energy conservation measures. These measures resulted in combined design saving 27.4\%, HVAC system saving $10.6 \%$, implementation of standards saving about $16.7 \%$, lighting $6.6 \%$, equipment $2.6 \%$, Insulation $2.5 \%$ and glazing $1.4 \%$. The study attempted to provide energy conservation 
measures in public buildings, which is conducted with the aim of attracting some attention to the consequences of excess energy use in the environments.

\section{REFERENCES}

1. Flex Your Power., Boosting Restaurant Profits with Energy Efficiency: A Guide for Restaurant Owners and Managers. Efficiency Partnership, San Francisco, 2006.

2. Energy Star., Restaurants Factsheet: Energy Use and Energy Efficiency Opportunities in Restaurants.

http://www.energystar.gov/ia/business/small_business/restaurant_factsheet.pdf, Accessed on 1st October, 2011.

3. Zinzi, F., Understanding a Restaurant's Energy Use. Retrieved from http://ezinearticles.com/?Understanding-a-Restaurants-Energy-Use\&id=4010125 on 23th October, 2010.

4. Al-Ajmi, F. F., and Hanby, V. I., Simulation of energy consumption for Kuwaiti domestic buildings. Energy and Buildings, Vol. 40 pp. 1101-1109, 2008. (http://dx.doi.org/10.1016/j. enbuild.2007.10.010)

5. Al-Homoud M. S., The Effectiveness of Thermal Insulation in Different Types of Buildings in Hot Climates. Journal of Thermal Envelope and Building Science. SAGE Publications, Vol. 27, No. 235, 2004.

6. Kim, J., and Moon, J. W., Impact of Insulation on Building Energy Consumption. Proceedings of Eleventh International IBPSA Conference, Glasgow, Scotland, Building Simulation, 2009.

7. Bolin, R., HVAC Integration of the Building Envelope. National Institute of Building Sciences, Whole Building Design publication, retrieved from http://www.wbdg.org/resources/env_hvac_integration.php, 2009.

8. Iqbal, I., and Al-Homoud, M.S., Parametric analysis of alternative energy conservation measures in an office building in hot and humid climate. Building and Environment Vol. 42, pp. 2166-2177, 2007. (http://dx.doi.org/10.1016/j. buildenv.2006.04.011)

9. Radhi, H., A Systematic Methodology for Optimizing the Energy Performance of Buildings in Bahrain. Energy and Buildings, Vol. 40 pp 1297-1303, 2008. (http://dx. doi.org/10.1016/j. enbuild.2007.11.007)

10.Said, S. A. M., Habib, M. A., and. Iqbal, M. O., Database for building energy prediction in Saudi Arabia. Energy Conversion and Management Vol. 44 pp. 191-201, 2003. (http://dx.doi.org/10.1016/S0196-8904(02)00042-0)

11.AlZain, M. A., Modelling Energy Use in the Commercial Sector in a Saudi Arabia Retail Store as a Case Study. University of Sharjah Journal of Pure \& Applied Sciences, Vol. 3, No. 2, 2006.

12.Al-Homoud, M. S., Abdou, A. A., and Budaiwi, I. M., Assessment of monitored energy use and thermal comfort conditions in mosques in hot-humid climates. Energy and Buildings, Vol. 41 pp. 607-614, 2009. (http://dx. doi.org/10.1016/j.enbuild.2008.12.005)

13.Ardehali, M. M., and Smith, T. F., Evaluation of HVAC System Operational Strategies for Commercial Buildings. Energy Conversion and Management Vol. 38, No. 3, pp. 225-236, 1997. (http://dx.doi.org/10.1016/S0196-8904(96)00039-8)

14.VanGeem, M. G., Energy Codes and Standards. National Institute of Building Sciences, Whole Building Design, Retrieved from http://www.wbdg.org/resources/energycodes.php, 2010.

15.Stegou-Sagia, A., Antonopoulos, K., Angelopoulo, U., and Kotsiovelos, G., The Impact of Glazing on Energy Consumption and Comfort. Energy Conversion and Management Vol. 48 pp 2844-2852, 2007. (http://dx. doi.org/10.1016/j.enconman.2007.07.005) 
16.Al-Azhari, F. B., Al-Abbadi, N. M., and Al-Natheer, O. A., Case Studies of Energy Conservation Opportunities in the Commercial Sector in Riyadh, Saudi Arabia. Proceedings of The First Symposium on Energy Conservation \& Management in Buildings, Impact on the national economy, KFUPM Saudi Arabia, 2002.

17.ASHREA, Energy Code for Commercial and High-rise Residential Buildings; ASHRAE/IES 90.1-1989, Energy Efficient Design of New Buildings except Low Rise Residential Buildings. American Society of Heating Refrigerating and Air-conditioning Engineers, INC. 1998.

18.IECC. 2000 International Energy Conservation Code. IECC, JCBO, 2000.

19.Iwaro, J., and Mwasha, A., Implications of building energy standard for sustainable energy efficient design in buildings. International Journal of Energy and Environment, Vol. 1, Issue 5, pp.745-756, 2010.

20.Birner, S., Martinot, E., The GEF Energy-Efficient Product Portfolio: Emerging Experience and Lessons. Washington DC, 2002.

21.Hasegawa, T., and Organisation for Economic Co-operation and Development. Environmentally sustainable buildings: challenges and policies. OECD, Paris, 2003. 